\title{
EKSPLORASI RUANG KOMUNAL DAN INFORMAL DI KEHIDUPAN KAMPUNG KOTA JAKARTA DALAM PROYEK BALAI BUDAYA KOLEKTIF DAN ANAK PASEBAN
}

\author{
Olivia Nadya ${ }^{1)}$, Suryono Herlambang ${ }^{2)}$ \\ 1)Program Studi S1 Arsitektur, Fakultas Teknik, Universitas Tarumanagara, olivianadya@hotmail.com \\ 2)Program Studi S1 PWK, Fakultas Teknik, Universitas Tarumanagara, s.herlambang@gmail.com
}

Masuk: 06-07-2020, revisi: 31-07-2020, diterima untuk diterbitkan: 23-09-2020

\begin{abstract}
Abstrak
Sebagai perpaduan antara Kota (kota formal) dan Kampung (desa tradisional), 'rasa' kota Jakarta dapat ditemukan di kampung-kampung kota dimana banyak penduduk membentuk komunitas yang kuat. Komunitas tersebut menghasilkan sebuah tipologi baru yang akan terus berubah dan berkembang sesuai adaptivitas warganya. Dengan memandang ruang komunitas bersama sebagai elemen penting berkehidupan di kota, perkembangan kampung kota seharusnya berfokus pada ruang bersama ini, yang memiliki makna pada: penggunaan ruang, budaya masyarakat sipil, dan prasarana sebagai proses menyelaraskan berbagai jalan hidup sehari-hari perkotaan. Kampung kota menjadi contoh dimana praktik ruang bersama ini banyak ditemukan dalam kehidupan sehari-hari. Dengan pendekatan metode eksplorasi arsitektur naratif yang berdasarkan skenario kehidupan sehari-hari para warga, ruang-ruang yang terbentuk akan menjadi 'rumah kedua' bagi warga lokal dan juga menjadi Ruang Ketiga bagi para penggunanya. Proyek 'Balai Budaya Kolektif dan Anak Paseban' memberikan ruang bersama publik terancang, bagi warga Kampung Kramat Sawah dan Kramat Lontar di Kelurahan Paseban, Kecamatan Senen, berdasarkan partisipasi komunitas dalam aspek sosial-budaya-rekreasional yang juga dapat memberikan edukasi non-formal dan penghidupan ekonomi produktif bagi warganya melalui pemberdayaan komunitas. Sehingga dapat diraihnya kampung yang selain sebagai ruang produksi sosial habitat, tetapi juga produktif secara ekonomi, sesuai dengan karakter kelokalannya.
\end{abstract}

Kata Kunci: Balai Warga; Kampung Kota; Pemberdayaan Masyarakat; Ruang Ketiga; Ruang Sosial Informal

\begin{abstract}
As a combination of Kota (formal city) and Kampung (traditional village), the 'taste' of Jakarta can be found in urban villages where many residents formed strong communities. The community produces a new typology that will continue to change and develop according to the adaptability of its citizens. By viewing shared space or commons as an important element of living in cities, urban village development should focus on this commons, in which has a meaning on the use of space, civil society culture, and infrastructure as a process of aligning various urban daily life paths. Urban villages are an example where the practice of shared space is found in daily life. With a narrative architectural exploration method approach based on the scenarios of people's daily lives, the spaces that are formed will become a 'second home' for local residents and also a Third Place' for its users. The 'Paseban Collective Culture and Children Hall' Project provides a designated public space, for residents of Kampung Kramat Sawah and Kramat Lontar in Paseban Village, Senen District, based on community participation in socio-culturalrecreational aspects which can also provide non-formal education and productive economic livelihood for its citizens through community empowerment. So that urban villages are not only as a social production space for habitats, but are also economically productive, according to its local character.
\end{abstract}

\section{Keywords: Community Empowerment; Community Hall; Informal Social Space; Third Space; Urban Village}




\section{PENDAHULUAN \\ Latar Belakang}

Menduduki negara terpadat di dunia ke-17, Jakarta mempunyai kepadatan penduduk mencapai 16.000 penduduk per km2. Pertumbuhan penduduk pun masih bertambah, namun tidak diiringi dengan sumber daya manusia (SDM) yang memadai. Banyak migran dari luar Jakarta yang ingin mengadu nasib di daerah pusat perekonomian ini, mencari kehidupan di kampung-kampung kota Jakarta. Menurut John Friedmann (2007), terdapat 7 kelompok aset tangible yang bersifat mendasar bagi sebuah kota: aset manusia, aset sosial, aset budaya, aset intelektual, aset alam, aset lingkungan, dan aset perkotaan. Seiring waktu, interaksi antar aset kota tersebut membentuk kearifan lokal yang dikenal dengan istilah "commons". Commons memiliki makna pada penggunaan ruang, budaya masyarakat sipil, dan prasarana sebagai proses menyelaraskan beragam jalan hidup sehari-hari perkotaan. Dalam praktiknya, kampung kota menjadi contoh dimana praktik commons banyak ditemukan dalam kehidupan seharihari. Dengan memandang commons sebagai elemen penting berkehidupan di kota, perkembangan kampung kota seharusnya berfokus pada lingkungan manusia dengan seluruh kualitas, baik berwujud maupun yang tidak berwujud. Perencanaan dan pengelolaan kekayaan kampung kota, harus dilakukan secara holistik dengan tujuan pembangunan sosial dan ekonomi. Termasuk upaya melanjutkan perencanaan dan perancangan intervensi dengan mempertimbangkan lingkungan binaan yang ada, warisan yang bukan benda, keanekaragaman budaya, faktor sosial-ekonomi dan lingkungan bersama dengan nilai-nilai masyarakat setempat.

\section{Rumusan Permasalahan}

Berdasarkan latar belakang, rumusan masalah yang didapat antara lain:

a. Bagaimana pembentukan sebuah third place atau commons yang berfokus kepada partisipasi warga lokal dan memberikan kontribusi positif bagi para warganya?

b. Bentuk program apa saja yang dibutuhkan untuk menunjang aktivitas yang ada di kampung kota dan bertujuan untuk meningkatkan sense of communitynya?

\section{Tujuan}

Tujuan dari proyek ini untuk menjawab rumusan permasalahan diatas, antara lain:

a. Mempelajari bagaimana praktik commons dalam kehidupan keseharian warga kampung kota berpengaruh kepada pembentukan ruang

b. Mengeksplorasi program yang dapat menunjang aktivitas di kampung kota

c. Memberikan ruang publik terancang berdasarkan partisipasi komunitas atau warga lokal

\section{KAJIAN LITERATUR}

\section{Third Place}

Manusia menginginkan rasa nyaman dan rasa kepemilikan akan suatu tempat. Sebagai makhluk sosial tentu juga membutuhkan tempat-tempat di mana mereka merasa welcomed dan terhubung. 2nd place (tempat kerja) adalah pengalaman sosial yang terstruktur dan formal dan 1st place (rumah) adalah pengalaman pribadi, tempat ketiga adalah lingkungan yang lebih santai di mana orang merasa nyaman dan tempat mereka kembali waktu untuk bersosialisasi, bersantai, dan menikmati kebersamaan dengan orang-orang di sekitar mereka. Third place tidak hanya berakar sebagai bagian dari gaya hidup kita, tetapi telah menjadi aspek penting dalam menjalani kehidupan sehari-hari (Oldenburg, 1989). Dalam artikelnya yang berjudul The Welcome Resurgence of 'Third Places', Jay Kapoor membahas: Ruang Ketiga ini terbangun dari community (komunitas), menimbulkan sebuah sense of community, dimana para pengguna memiliki rasa memiliki, perasaan bahwa masing-masing penggunanya penting bagi satu sama 
lain. Community sendiri terbangun atas prinsip-prinsip: kesamaan akan individu, tempat di mana orang berinteraksi, dan dapat menarik orang untuk masuk tanpa upaya besar.

Menurut Project for Public Spaces, place dapat dimaknai sebagai sebuah space yang memiliki keterikatan emosional dengan penggunanya. Proses yang dilakukan untuk menciptakan atau mengembangkan suatu tempat disebut sebagai Placemaking. Bagaimana peran masyarakat dalam membuat suatu tempat (atau tempat ketiga) yang baik? Placemaking merupakan suatu upaya pendekatan multi-sisi dan -disiplin untuk perencanaan, perancangan, dan pengelolaan ruang publik. Memanfaatkan aset yang ada, inspirasi, dan potensi dengan tujuan menciptakan ruang publik yang mempromosikan kesehatan, kebahagiaan, dan kesejahteraan masyarakat. Sehingga dapat ditarik rangkuman bahwa:

a. Third place mewakili pengalaman pribadi

b. Third place memenuhi kebutuhan individu, dan masing-masing berbeda

c. Third place menjadi tempat rehat dari rumah dan bekerja, namun mereka sama pentingnya dengan keduanya

d. Tempat Ketiga secara fungsional secara personal

e. Tempat Ketiga ada ketika kita membutuhkannya

f. Tempat Ketiga didasarkan pada komunitas lokal

g. Placemaking adalah cara untuk membuat third place yang berorientasi komunitas

\section{Kampung Kota Jakarta}

Jakarta dapat dipahami sebagai perpaduan antara Kota (kota formal) dan Kampung (desa tradisional). 'Rasa' kota dapat ditemukan di kampung-kampung ini, dimana $60 \%$ hingga $80 \%$ penduduk Jakarta tinggal. Dengan adanya Kampung, banyak penduduk membentuk komunitas yang kuat. Desa-desa berbasis darat ini menyediakan pekerjaan, layanan, dan perumahan bagi penduduk dengan berbagai spektrum keberagaman etnis, struktur sosial, dan tingkat pendapatan. Namun Kampung Kota menghadapi banyak masalah serius, mulai dari yang sangat mendasar, seperti infrastruktur yang buruk hingga banyak masalah kota yang kompleks dan saling terkait.

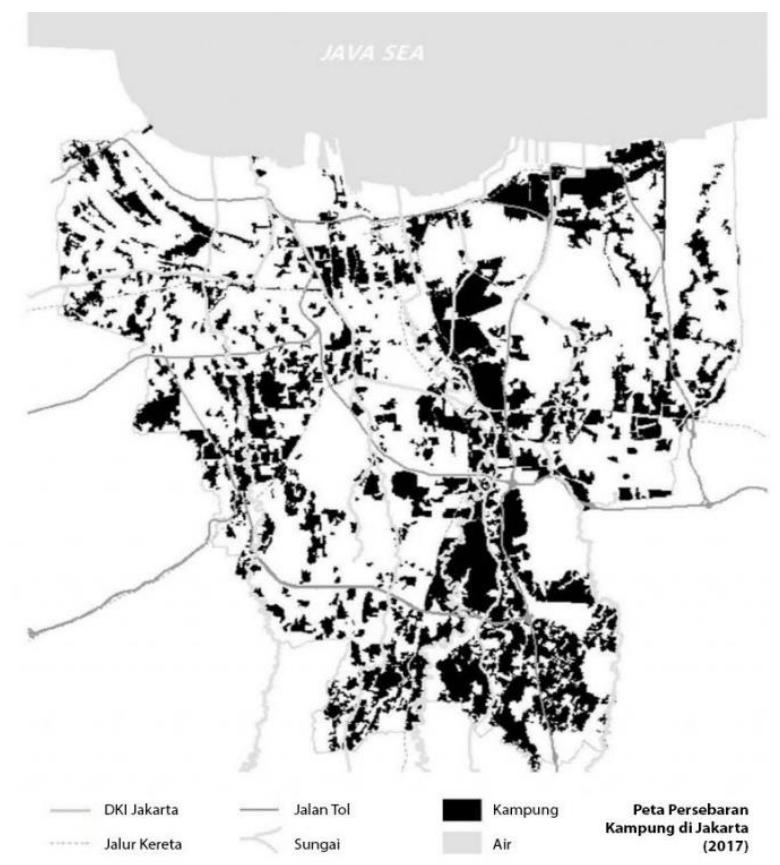

Gambar 1. Perkembangan Kampung di Jakarta

Sumber: Rujak Center of Urban Studies, 2019 
Menurut Rujak Center for Urban Studies, jutaan orang di Jakarta menjadikan kampung sebagai tempat tinggalnya. Biasanya, para penghuni kampung adalah masyarakat berpenghasilan rendah atau pendatang yang bekerja di Jakarta. Interaksi yang intens dari para penduduk ini membentuk wajah kampung. Meski kampung sering dilabeli beragam sentimen negatif, ia tetap dihuni oleh warganya. Pasalnya, kampung menyediakan tempat murah, juga menjadi tempat transisi manusia yang nyaman bagi pendatang dari desa. Kenyamanan itu didasari sistem hidup di kampung yang identik dengan fleksibilitas dan ketahanan, serta kemampuannya menjadi ruang yang melampaui relasi sosial kapitalis. la bisa menjadi oase bagi penghuni kota, yang sehari-hari harus berhadapan dengan ketimpangan ekonomi dan kompetisi.

Warga kampung melihat habitatnya sebagai ruang penting untuk banyak hal: tempat tinggal, lapak berdagang, ruang bermain, sekaligus sarana bersosialisasi. Gang kampung biasanya menjadi ruang interaksi utama sosial, aktivitas yang saling tumpang tindih dengan fungsi utama gang kampung sebagai ruang sirkulasi manusia dan barang. Sempitnya gang membuat pejalan kaki menjadi aktor utama, dengan kekuasaan melebihi pengguna kendaraan bermotor. Adapun gang buntu biasanya difungsikan sebagai halaman komunal tempat warga bisa berkumpul. Bentuk gang kampung turut mempengaruhi interaksi dan aktivitas manusia di dalamnya. Di sini, arsitektur kampung membentuk dan dibentuk oleh warganya.

\section{Kampung Kota sebagai ruang produksi sosial habitat}

Rujak Center for Urban Studies dalam studinya 'Kenal Kampung Kota' (2018) menyebutkan kampung kota merupakan salah satu bentuk pemukiman dengan karakteristik yang unik. Keterbatasan akses terhadap pelayanan publik baik fisik dan non-fisik, malah menghasilkan komunitas yang solid dan menjadi modal dalam mengatasi keterbatasan yang ada. Interaksi dan jaringan sosial dari para pemukim kampung kota ini dapat disebut sebagai modal sosial, seperti sebagaimana baik mereka mengenal tetangga, mengadakan acara bersama, dan sebagainya. Secara spasial hal ini ditunjukkan melalui keberadaan dan aktifnya ruang-ruang publik, seperti lapangan olahraga, taman, tempat bermain, ruang serba guna, dan sebagainya.

Sempitnya ruang di dalam kampung membuat warga kreatif memanfaatkannya. Gang adalah solusi untuk banyak masalah, termasuk kurangnya ruang menjemur pakaian warga, ruang bermain anak-anak, hingga puluhan warung yang memenuhi gang kampung. Menjadi warga kampung berarti pandai bersiasat, penghuni kampung mengembangkan kemampuan bertukang yang memungkinkan untuk mereka, menciptakan infrastruktur informal, dari inisiatif warganya tersendiri. Inilah produksi sosial habitat, yang mencakup proses dan produk yang timbul dari inisiatif bersama masyarakat dalam membangun habitatnya. Mereka merancang, membangun, dan merawat ruang hidup serta komponen perkotaan atau pedesaan. Mereka mencari solusi bagi masalah di rumah dan kampungnya, lantas melaksanakan solusi itu bersama-sama.

Fenomena ini dapat mewujud dalam banyak hal, mulai dari perbaikan dan pengembangan rumah yang sudah ada, produksi sarana umum baru, perbaikan kampung. Produksi sosial habitat, terutama yang didukung oleh proses kolektif, dapat berkontribusi memperkuat masyarakat, demokrasi, rasa percaya diri penghuni kampung, dan kerukunan warga. Dan dapat berperan strategis dalam perjuangan mengatasi kemiskinan dan ketimpangan masyarakat. Dengan produksi sosial habitat, investasi untuk meningkatkan produktivitas warganya dengan perekonomian. 


\section{Peran Komunitas dalam Kehidupan Kampung Kota}

Komunitas yang aktif dapat membentuk inisiatif yang akhirnya membawa pemberdayaannya, salah satunya dalam pembentukan Komunitas Anak Kali Ciliwung (KAKC). Merupakan gabungan dari tiga kampung yang berdekatan di bantaran Sungai Ciliwung, yaitu Kampung Kerapu, Kampung Tongkol, dan Kampung Lodan; KAKC menjadi wadah untuk menyalurkan aspirasi warganya untuk menjalankan kegiatan-kegiatan pemberdayaan masyarakat, khususnya di bidang kebersihan Sungai Ciliwung, urban farming hingga pembuatan IPAL (Amalina, 2017). Selain itu terdapat juga Kampung Kreatif Bacili (Bantaran Ciliwung) yang merupakan hasil kerja swadaya masyarakat setempat untuk mengubah wilayah mereka yang terkenal rawan konflik menjadi kampung kreatif yang damai, bersahabat dan asri dengan lukisan gambar-gambar yang menarik, dengan menggandeng sejumlah pihak eksternal seperti mahasiswa sebagai penggerak yang kemudian dilanjutkan oleh kesadaran warganya sendiri.

\section{METODE}

\section{Metode Penelitian}

Sebelum masuk ke dalam proses perancangan, penulis melakukan tahapan penelitian untuk pengumpulan data sebagai dasar perancangan dengan sebagai berikut:

a. Pengumpulan Studi Literatur

Mengkaji mengenai definisi dan apa yang menjadikan sebuah Third Place dari buku Ray Oldenburg 'The Great Good Place' dan metode Placemaking menurut Project for Public Spaces. Kedua, mengenai kehidupan kampung kota di Jakarta secara general, bagaimana kehidupan di dalamnya, dan mencari tahu lebih lanjut bagaimana sebuah komunitas kampung dapat berkelanjutan dan memberi dampak positif ke komunitasnya sendiri, dan bagaimana warganya mendefinisikan kampung bagi dirinya masing-masing.

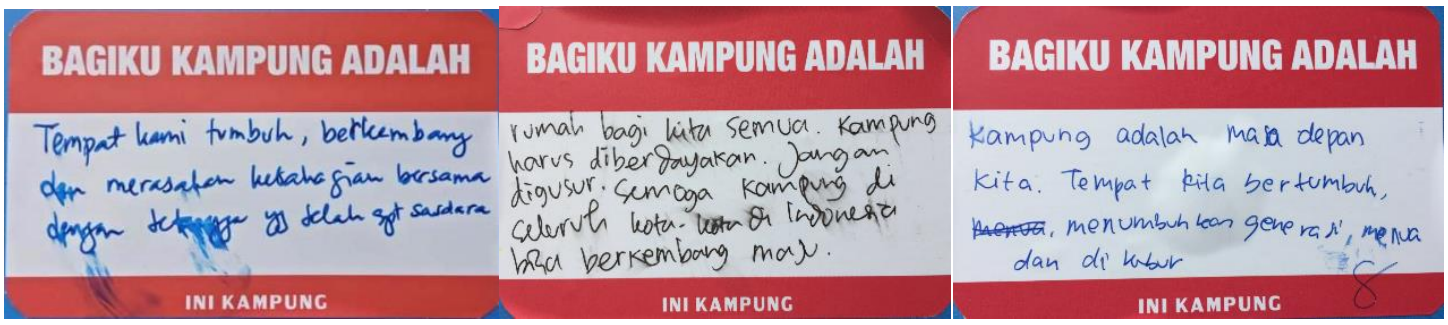

Gambar 2. Opini Masyarakat terhadap Kampungnya

Sumber: Pameran Ini Kampung, Dok. pribadi, 2019

b. Survey Lapangan

Survey lapangan dilakukan untuk merekam berbagai fenomena yang terjadi di tapak, yaitu Kampung Kramat Sawah dan Kramat Lontar, Kelurahan Paseban, Jakarta Pusat. Dilakukan wawancara terhadap beberapa warga lokal untuk mencari tahu karakter khusus dari kampung tersebut. Selain wawancara, penulis melakukan observasi lingkungan untuk mencari potensi atau masalah yang tangible terhadap tapak dan proyek, contohnya: adanya potensi untuk mahasiswa dapat melakukan pengabdian masyarakat karena adanya sejumlah kampus dalam lingkup radius $1.5 \mathrm{~km}$ dari tapak.

\section{Metode Perancangan}

Metode perancangan arsitektur dengan pendekatan naratif merupakan salah satu cara untuk mengolah cerita menjadi ruang ataupun memproduksi cerita baru di dalam sebuah ruang. Arsitektur naratif lebih mengedepankan bagaimana perancang dapat menceritakan atau menggambarkan pengalaman keruangan dan sense of place. Narasi sendiri dapat dideskripsikan sebagai perjalanan ruang dan waktu, dimana di dalamnya terekam sebuah timeline ruang. Perancangan berbasis narasi ini dapat menggunakan berbagai macam yang biasanya dilakukan untuk memproduksi atau menyampaikan sebuah cerita, misalnya dengan 
menghasilkan sebuah cerita baru, menyunting kata-kata, mengubah urutan kejadian, hingga membuat berbagai macam skenario keadaan. Menurut Nigel Coates, narasi pada dasarnya mengakar pada sebuah tempat yang dihuni dan ada hubungannya dengan apa yang selama ini dialami oleh penghuninya. Narasi ini juga membentuk dan menyederhanakan peristiwa menjadi urutan yang dapat merangsang imajinasi dan harapan lainnya. Melalui metode ini, karya arsitektur dapat menjadi wahana bagi lapisan narasi dan memiliki potensi untuk lebih melibatkan pengalaman manusia, memperhitungkan isu yang terkait dalam pengalaman sensasi, asosiasi, perkumpulan, bergaul, dan rasa memiliki.

Kemudian Sophia Psarra dalam bukunya Architecture and Narrative (2009) menuturkan bahwa pendekatan naratif adalah salah satu metode untuk mengevaluasi cerita dari suatu tempat baik sebagai pendekatan konseptual, proses desain, dan media komunikasi. Penelitian ini akan mempertimbangkan hubungan antara cara ruang arsitektur, gerakan dan pengalaman yang dikonseptualisasikan, bagaimana perkembangan itu diterjemahkan dengan proses perancangan desain dan akhirnya menjadi proyek. Arsitektur narasi membawa konten melalui pengaturan ruang, material, hubungan sosia, dan tujuan yang diinvestasikan. Narasi sendiri berasal dari kata narratio, yang berarti cerita. Hubungan antara cerita dan narasi dapat dibagi menjadi 2 aspek, yaitu cerita itu sendiri, konten, dan percakapan, dan ekspresi atau bagaimana hal itu diceritakan. F.E. Tissink membahas dalam Narrative-drive Design (2006), narasi adalah sebuah interaksi ganda, sama halnya seperti bagaimana arsitektur memerlukan seorang arsitek dan pengguna. Di sinilah arsitektur dan naratif bertemu. Arsitek memberikan bentuk terhadap sebuah ruang dengan konteks/cerita yang berbeda-beda. Bagaimana mereka bisa relevan dengan desain arsitektur dan peran apa yang bisa mereka mainkan untuk desainer? Peran naratif dalam arsitektur adalah sebagai berikut:

a. Linking hubungan

Menghubungkan lingkungan dan identitas. Melalui narasi, cerita, kejadian dan memori, seseorang bisa merasakan koneksi terhadap lingkungan yang membentuk sebuah identitas.

b. Structuring/Kerangka

Arsitektur naratif juga memiliki peran menambahkan kerangka cerita terhadap sebuah pengalaman ruang. Dengan menambahkan kerangka cerita maka arsitek dapat menentukan program, kebutuhan ruang, serta bentuk fisik suatu bangunan yang menyesuaikan proses dan pengalaman ruang berdasarkan alur cerita.

c. Framing/Pembingkaian

Pembingkaian merupakan upaya arsitektur naratif untuk memanipulasi persepsi seorang subjek dengan pembingkaian, seseorang akan diarahkan menuju perspektif tertentu, melalui rute yang telah ditetapkan, dan tertarik terhadap elemen tertentu yang bertahap yang dirancang oleh seorang arsitek.

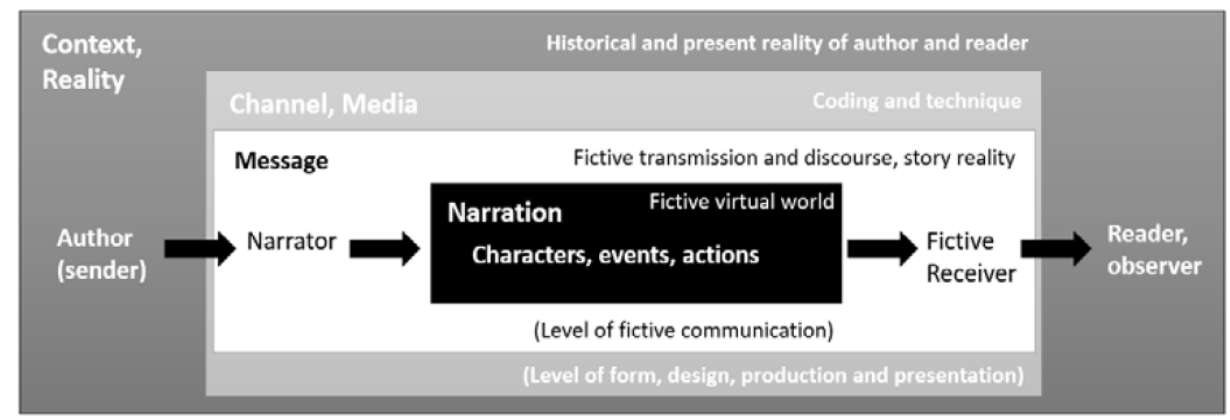

Gambar 3. Framework Arsitektur Naratif

Sumber: Narrative-driven design, F.E. Tissink, 2016 


\section{Collective Memory}

Aldo Rossi menyatakan konsep yang menekankan pada kumpulan fragmen yang membentuk suatu memori kolektif bagi sebuah kota. Kota tidak hanya dilihat sebagai physical artifacts, namun sebagai representasi dari aspirasi manusia dalam ruang dan waktu. Dengan jejak yang ditinggalkan oleh sebuah kota, Rossi mengenalkan istilah permanence sebagai sebuah kontinuitas urban types dengan menggambarkan cara pandang terhadap arsitektur yang seharusnya tidak sebagai elemen yang mati melainkan sebagai suatu elemen yang hidup atau dinamis. Kehadiran sebuah piazza, bangunan, ataupun sebuah kota tidak seharusnya hanya berhenti sebagai suatu elemen yang hadir begitu saja, melainkan dipahami sebagai suatu catatan, informasi, ataupun suatu kesinambungan dengan aspirasi hidup masyarakat didalamnya.

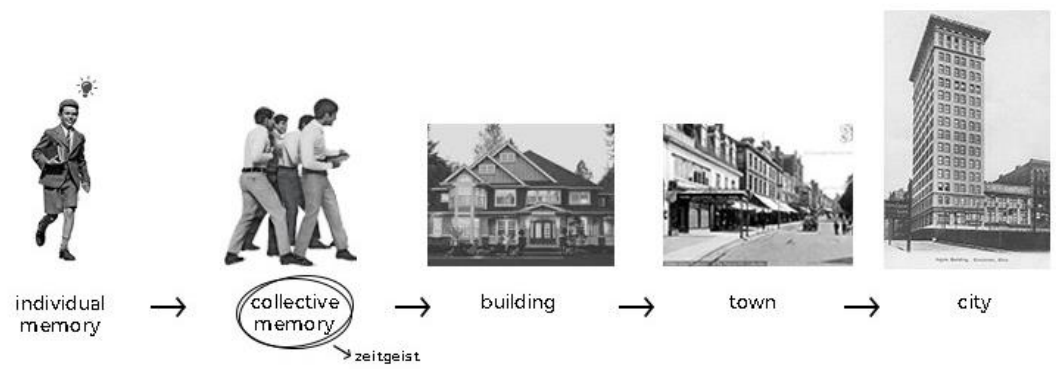

Gambar 4. Diagram Memori Kolektif yang Membentuk Kota

Sumber: Artikel Medium tHEORY 101: Aldo Rossi's Collective Memory oleh heryantosalim, 2018

Memori kolektif mengacu pada kumpulan memori, pengetahuan, dan informasi bersama dari suatu kelompok sosial yang secara signifikan terkait dengan identitas kelompok. Penggalian memori kolektif dari warga lokal, cerita apa yang mereka rasakan baik saat ini ataupun dahulu, yang mereka harapkan, apa yang mereka ingat dapat menceritakan identitas dan karakter kampung tersebut dan apa efeknya ke penghuninya. Melalui wawancara kepada warga lokal, memori kolektif dapat menjadi sebuah storyboard rekaman warga terhadap suatu peristiwa, ingatan sekumpulan orang yang terkumpul karena pengalaman yang sama, bahkan dapat menjadi identitas kawasan.

\section{DISKUSI DAN HASIL}

\section{Analisis Lokasi}

\section{Pertimbangan Pemilihan Lokasi}

Dalam pemilihan lokasi kawasan yang spesifik, ada beberapa pertimbangan yang perlu diperhatikan, meliputi:

a. Permukiman padat penduduk berupa kampung kota: sebagai ruang produksi sosial habitat bagi mayoritas penduduk kota dan migran. Kampung kota yang terpilih memiliki rasio kepadatan hunian tinggi yang tidak seimbang dengan tersedianya kebutuhan akan tempat rekreasi (third place).

b. Lokasi tapak dekat dengan titik-titik keramaian, dengan contoh: sekolah, taman bermain, moda utama menuju tempat kerja dalam radius walking distance: proyek sebagai tempat singgah dari kehidupan sehari-hari (continuum) warga.

c. Aksesibilitas dalam lingkup seminimalnya kelurahan mudah, minimal lebar jalan utama dapat dilewati 2 mobil $( \pm 6 \mathrm{~m})$ untuk memudahkan perpindahan pengguna.

d. Penghuni kampung setidaknya sudah mempunyai atau aware dengan rasa kebersamaan (sense of community), kepemilikan, dan keinginan untuk berekspresi.

Berdasarkan kriteria di atas, tapak yang diangkat diambil di Kampung Kramat Sawah dan Kramat Lontar, Kelurahan Paseban, Kecamatan Senen, Jakarta Pusat. 


\section{Kampung Kramat Sawah dan Kramat Lontar, Kelurahan Paseban}

Kelurahan Paseban memiliki kepadatan penduduk mencapai 41.000 jiwa per $\mathrm{km}^{2}$, namun hanya memiliki 1 lapangan terbuka, yaitu Lapangan Perintis, seluas $80 \mathrm{~m}^{2}$, Kelurahan ini juga memiliki institusi pendidikan negri formal terbanyak di Kecamatan Senen, sebanyak 13 Sekolah Dasar (SD) dan 1 Sekolah Menengah Kejuruan (SMK). Nama 'paseban' merupakan bagian depan rumah adat Betawi sebagai tempat menerima tamu. Selain itu paseban yang berasal dari kata seba yang berarti menghadap (raja dan para petinggi kerajaan), disinyalir Kampung Paseban dulu menjadi tempat para kepala pasukan Kerajaan Mataram menghadap komandan yang memimpin penyerbuan ke Batavia pada tahun 1628-1629, yang mana tak jauh dari pusat komando pasukan Mataram (sekarang Matraman). Kampung Kramat Sawah dan Kramat Lontar diapit oleh Jalan Kramat Raya dan juga rel kereta api dan dipisahkan oleh Kali Sentiong. Dengan kepadatan tinggi, warga hanya memiliki 1 ruang terbuka sebagai tempat berkumpul warga, yaitu Lapangan Perintis, dan sehingga terbentuklah banyak pos-pos kecil sebagai tempat berkumpul cluster-cluster kecil yang memenuhi pinggir Jalan Kramat Sawah.

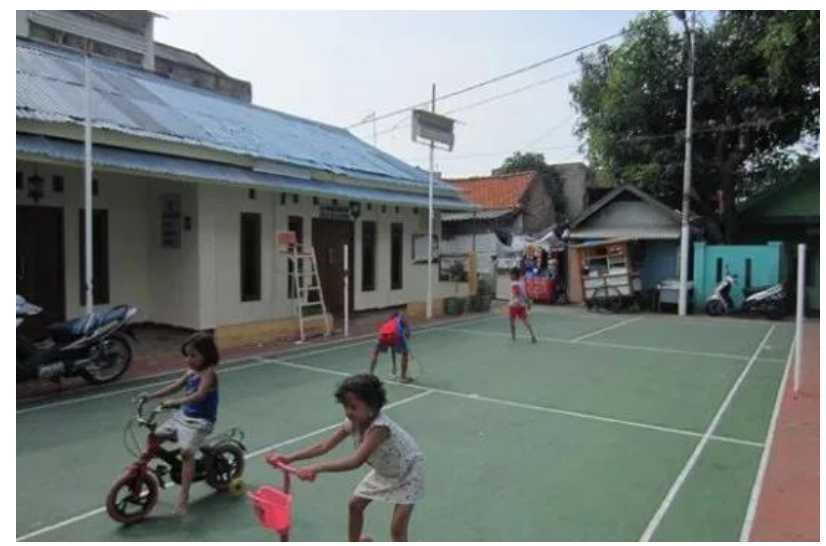

Gambar 5. Lapangan Perintis

Sumber: Dok. pribadi, 2020

Komunitas Budaya Paseban dibangun pada tahun 2000 oleh Gallis Agus Sunardi dan istrinya, Irawati, yang juga merupakan warga dari Kampung Kramat Sawah. Komunitas ini menjadi wadah edukasi bagi warga Kramat Sawah yang berbasis kesenian dengan mengembangkan metode pendidikan alternatif yang informal. Awalnya banyak melakukan program kesenian yang melibatkan anak-anak dan remaja, lalu muncul keinginan untuk membentuk sebuah ruang belajar dengan menggunakan teater sebagai dasar pijakan, karena melihat para ibu-ibu pun seringkali terlibat secara langsung dalam hampir setiap program Komunitas Budaya, berdirilah Teater Perempuan Paseban. Berbagai kegiatan dilakukan oleh ibu-ibu, bapak-bapak dan pemuda, maupun anak-anak. Kegiatan mereka sampai saat ini adalah teater, workshopworkshop, pameran, bazar murah, pemutaran film bahkan sampai kepada pengobatan gratis, baik medis maupun non-medis.

Namun sayangnya dengans banyaknya kegiatan, tidak didukung oleh tempat yang memadai. Selama ini warga hanya menggunakan Lapangan Perintis yang hanya seluas $60 \mathrm{~m}^{2}$ dan juga PAUD yang berada di sebelahnya, yang mana tidak dapat memuat banyak kegiatan dalam sekaligus, mengharuskan pergantian antar penggunanya. 

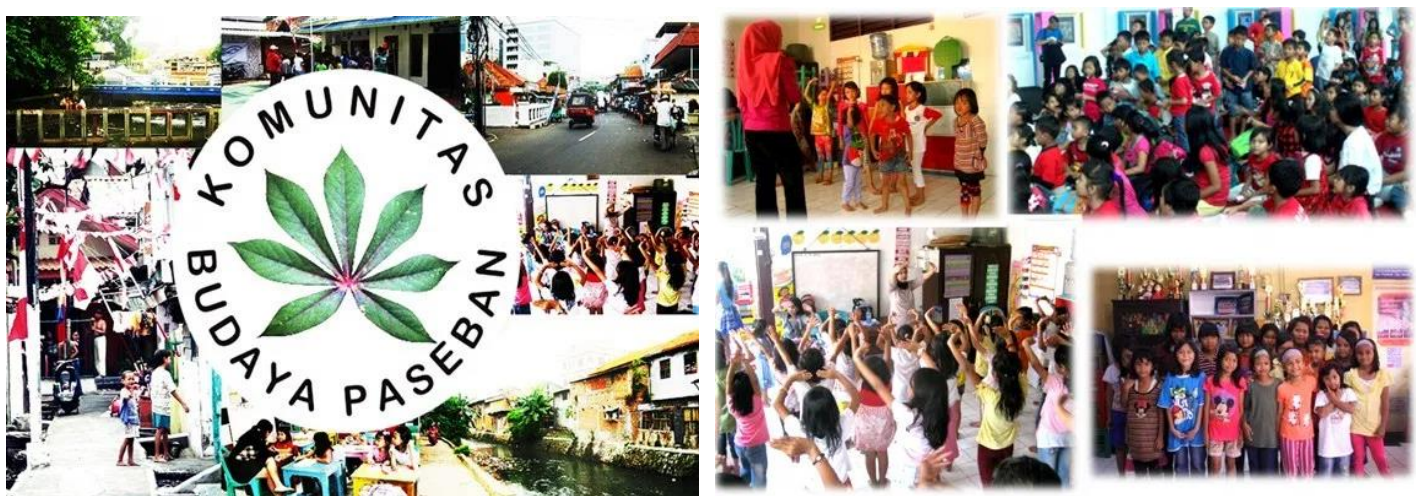

Gambar 6. Komunitas Budaya Paseban sebagai Wadah Pemberdayaan Masyarakat Sumber: akumassa.org, 2013
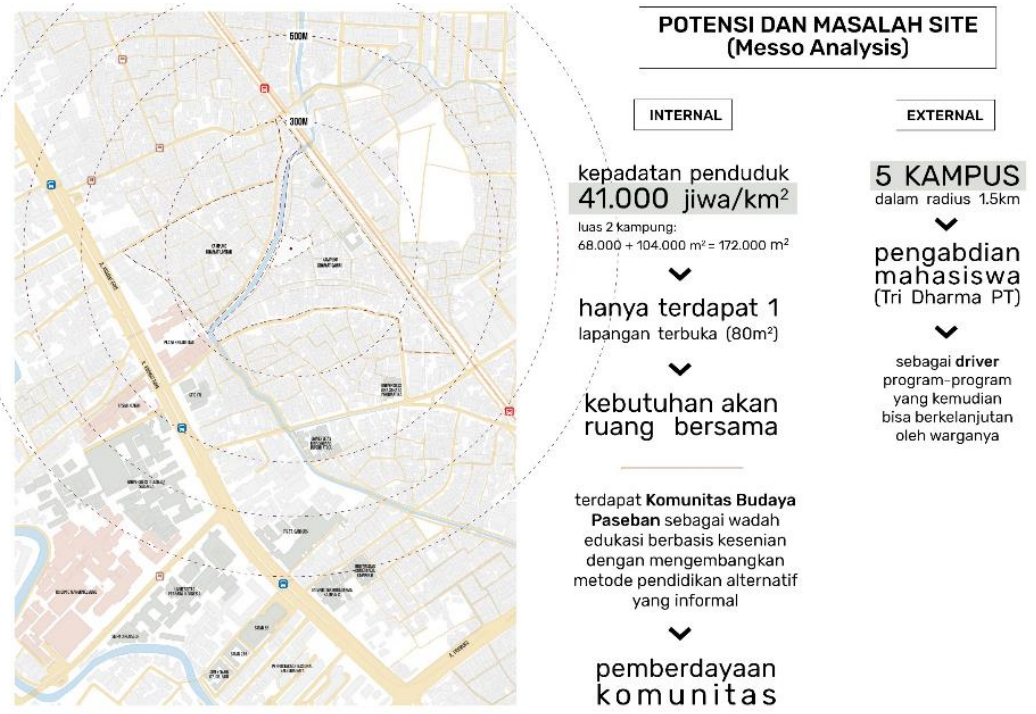

Gambar 7. Skema Rangkuman Potensi dan Masalah Site secara Messo Sumber: Dok. penulis, 2020

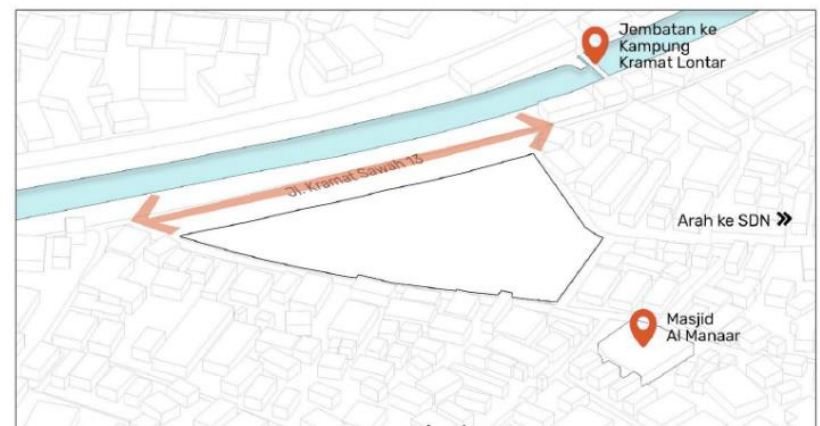

Gambar 8. Diagram Tapak (Mikro)

Sumber: Dok. penulis, 2020

Setelah melakukan survey lapangan, penulis memilih tapak untuk proyek ini di Jalan Kramat Sawah 13 yang berada di depan Kali Sentiong, dengan peruntukan zona campuran. Dikelilingi dengan berbagai fasilitas umum yang digunakan oleh warga lokal: SDN 01, 02, 03, 05 Paseban $(90 \mathrm{~m})$, Puskesmas Paseban $(120 \mathrm{~m})$, Sekolah Menengah Kejuruan Muhammadiyah $10(260 \mathrm{~m})$, PAUD Bahagia \& Lapangan Perintis $(260 \mathrm{~m})$, Kantor Kelurahan Paseban $(400 \mathrm{~m})$, Pasar Jaya Paseban (500m), Stasiun Gang Sentiong dan Stasiun Kramat (550m). Banyaknya fasilitas umum 
dengan fungsi edukasi, penulis memprediksikan program yang diajukan untuk proyek ini dalam bahasan bab proses program berikut.

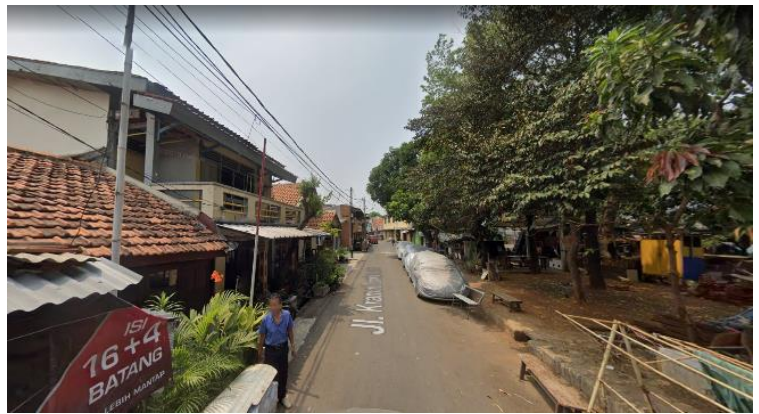

Gambar 9. Area Jl. Kramat Sawah - Jalan Utama (Posisi Tapak di Kiri) Sumber: Google Street View, 2020

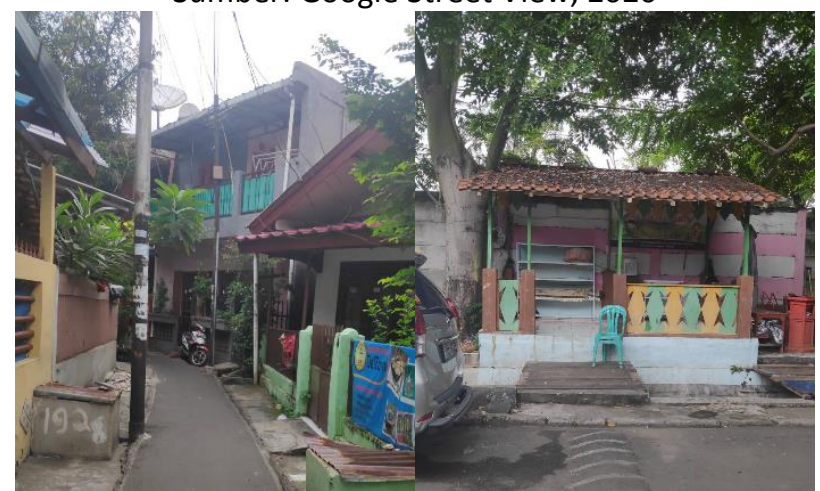

Gambar 10. Kiri: Gang di Sekeliling Tapak; Kanan: Sampel Pos-pos RT dan Siskamling sebagai Cluster Tempat Berkumpul Warga yang Ada di Sepanjang Jl. Kramat Sawah Sumber: Dok. pribadi, 2020

\section{Analisa kelokalan warga}

Karakter kampung sebagai tempat tinggal dan juga bekerja bisa dilihat dari elemen ruang bersamanya. Dari gang-gang, entrance masuk kampung, hingga jalan utama. Tipologi kemasyarakatan dapat terlihat oleh keanekaragaman adaptasi dan gotong royong oleh warga bisa terlihat dari elemen-elemen tersebut. Berupa: penyuluhan dan pemberdayaan warga, organisasi masyarakat yang menggerakan program, program hybrid dalam banguan, dan fisik seperti jalan yang di extend, barang yang digantung, dan gang sebagai ruang sosial.

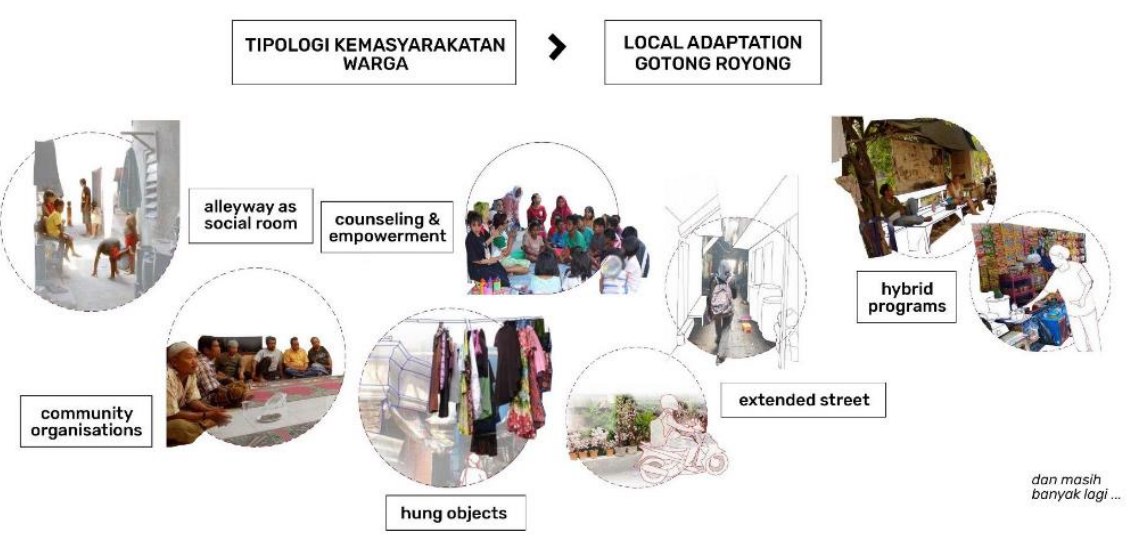

Gambar 11. Diagram Tipologi Kemasyarakatan Warga

Sumber: Dok. penulis, 2020 
PROSES PROGRAM

\section{Analisa Program Kegiatan}

Sebagai third place di kampung kota Kelurahan Paseban yang khas dengan karakteristiknya, proyek Balai Budaya dan Anak Paseban akan berdasarkan kebutuhan akan masyarakat dengan 3 aspek:

a. Aspek sosial-flexible program

Mencakup kebutuhan interaksi antar warga yang bertujuan untuk menciptakan keakraban dan sense of community.

- Balai warga

Sebagai pusat aktivitas kumpul bersama antarwarga di Kelurahan Paseban, khususnya di Kampung Kramat Sawah dan Kramat Lontar. Kegiatan dapat berupa penyuluhan warga, arisan, venue untuk hajatan warga atau sekedar tempat nongkrong dan berkumpul.

b. Aspek edukasi dan budaya - fixed program

Mencakup kebutuhan edukasi dan pemberdayaan komunitas untuk warga, khususnya anak-anak, remaja, dan ibu-ibu PKK. Selain itu juga menjadi sarana pelestarian budaya yang ada di kampung kota.

- Pelatihan seni tari, peran, dan kerajinan tangan

- Pelatihan teknologi dan elektronik

- Sanggar anak: tempat untuk anak-anak belajar suatu hal tertentu di luar kegiatan sekolah

- UKM PKK: tempat untuk ibu ART dan PKK membuat dan memasarkan usaha barang atau jasa

- Perpustakaan

c. Aspek rekreasi-flexible program

Mencakup kebutuhan rekreasi warga dari yang berdasarkan karakter kampung kota dan juga publik luas.

- Ruang serbaguna terbuka

Sebagai wahana entertainment warga dengan hiburan seperti layar tancap, dangdutan kampung, perayaan acara seperti tujuh belasan, pertandingan tarkam (antar kampung), hingga olahraga. Selain untuk warga, dapat dilakukan juga pertunjukan oleh komunitas warga yang berlatih di sanggar untuk audiens publik yang lebih luas.

\section{PROSES DESAIN}

\section{Analisa Konsep}

Kelokalan Kampung Kramat Sawah dan Kramat Lontar yang berasal dari budaya dan kebiasaan warganya menjadi konsep utama dalam proyek ruang ketiga ini. Dapat dilihat terdapat 8 tipe user yang dapat dianalisa kehidupan sehari-harinya untuk menjadi dasar dari pengembangan proyek.
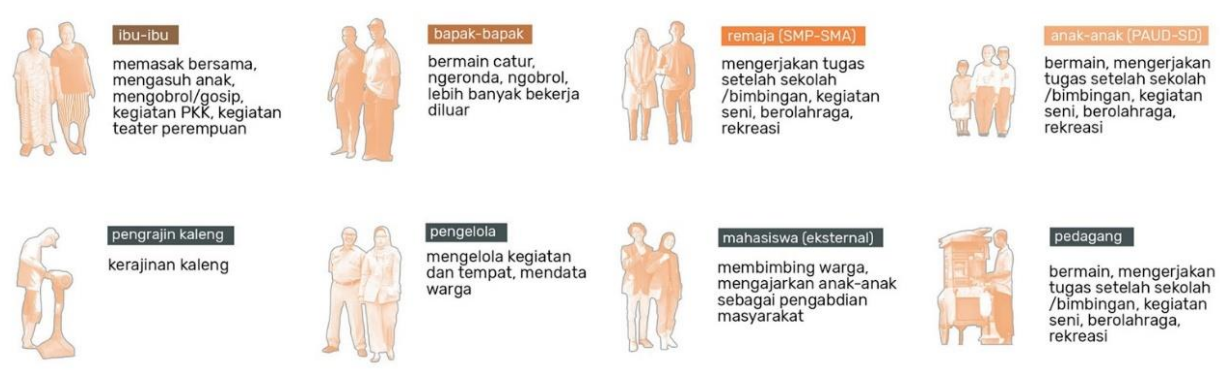

Gambar 12. Tipe Pengguna dan Aktivitasnya Sumber: Dok. penulis, 2020 
Dengan arsitektur naratif yang berdasarkan skenario berdasarkan kehidupan sehari-hari para warga, ruang-ruang yang terbentuk akan menjadi 'rumah kedua' bagi warga lokal dan juga menjadi ruang ketiga bagi para penggunanya. Nilai gotong royong terlihat dalam keseharian warga di kampung ini. Dari kegiatan memasak bersama ibu-ibu yang kemudian dibagikan ke masing-masing keluarganya, para pengrajin kaleng yang berdiskusi menjadikan kerajinan tersebut mata pencahariannya, ketukangan yang memenuhi gang-gang kampung seperti potpot bunga, pembuatan pos-pos berkumpul, serta Komunitas Budaya Paseban yang seringkali melakukan workshop seni untuk anak-anak yang berupa menggambar dan mewarnai, dan untuk ibu-ibu teater wanita.

Kesosialan para warga pun terlihat oleh ramainya gang-gang, rindang bawah pohon pinggir Kali Sentiong serta Lapangan Perintis di pagi hingga sore hari. Cukup dengan perbedaan peil lantai sehingga bisa diduduki, ruang sosial warga terbentuk dengan mudahnya. Adanya banyak kampus yang mengelilingi daerah tapak, memungkinkan terjadinya pemberdayaan warga melewati pengabdian mahasiswa untuk masyarakat. Selain itu terdapat juga pelatihanpelatihan oleh Kelurahan Paseban sendiri yang kantornya hanya berjarak kurang lebih 500 meter dari tapak. Sehingga dibutuhkannya ruang untuk mewadahi pelatihan tersebut. Banyaknya juga kebutuhan keterampilan untuk membantu para warga untuk menjadi salah satu kesempatan untuk menjadi ladang mata pencaharian warga lokal.

\section{Pengaplikasian Pengelompokan Program terhadap Tapak}

Dilihat analisa program kegiatan pada bab sebelumnya, program diurutkan dari nilai kefleksibilitasan hingga kepermanenan ruangnya (ditandai dengan warna merah - lebih fixed, warna kuning - lebih fleksibel). Kemudian ruang-ruang tersebut diimplementasikan dalam tapak dari ruang terfleksibel yang menghadap kali, dan ruang fixed yang menghadap ke belakang tapak.
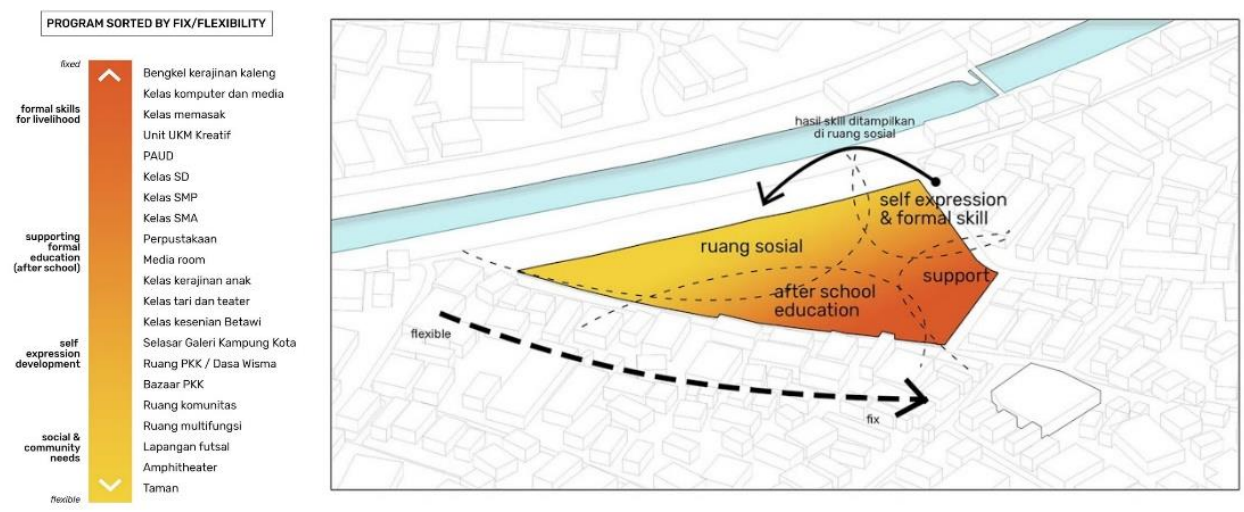

Gambar 13. Pengurutan Program dan Implementasi dalam Tapak Sumber: Dok. penulis, 2020

\section{Pembentukan Bangunan}

Program dipisah secara massa kecil yang kemudian digabungkan oleh platform sirkulasi yang memiliki orientasi terpusat kepada ruang-ruang sosial seperti gang utama dan juga lapangan terbuka. 


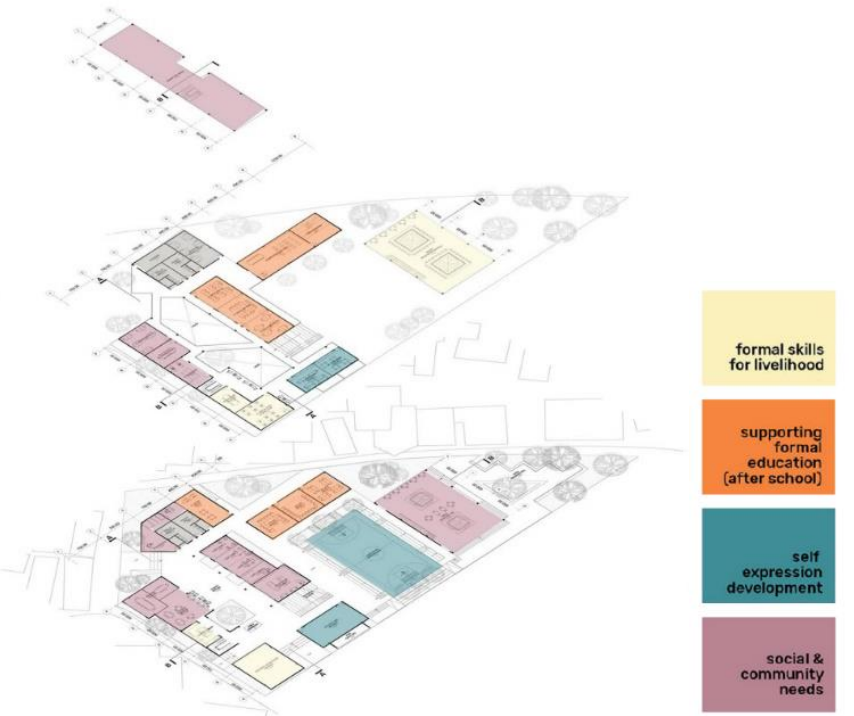

Gambar 14. Clustering Program Bangunan dalam Proyek Sumber: Dok. penulis, 2020

Bentukan bangunan pada dasarnya terbagi menjadi 3 pembagian zona. Pada sisi kiri bangunan massa-massa kecil dari fungsi program tergabung menjadi 1 dengan void dimana ruang antara membentuk sebuah gang utama sebagai ruang sosial dengan area terbuka. Dengan tangga utama yang menghadap ke lapangan multifungsi berfungsi sebagai tempat duduk ketika ada pertunjukan layar tancap atau pertandingan (zona 2). Pada sisi kanan, pada lantai dasar terdapat area jajan PKL yang sering berkumpul di depan tapak, terdapat tempat makan indoor dan juga outdoor untuk gerobak-gerobak jajanan dapat masuk ke area balai. Pada lantai 2, terdapat balai pemberdayaan dan pelatihan warga yang terbuka, selain kegiatan penyuluhan, area ini juga dapat digunakan sebagai area berkumpul santai.

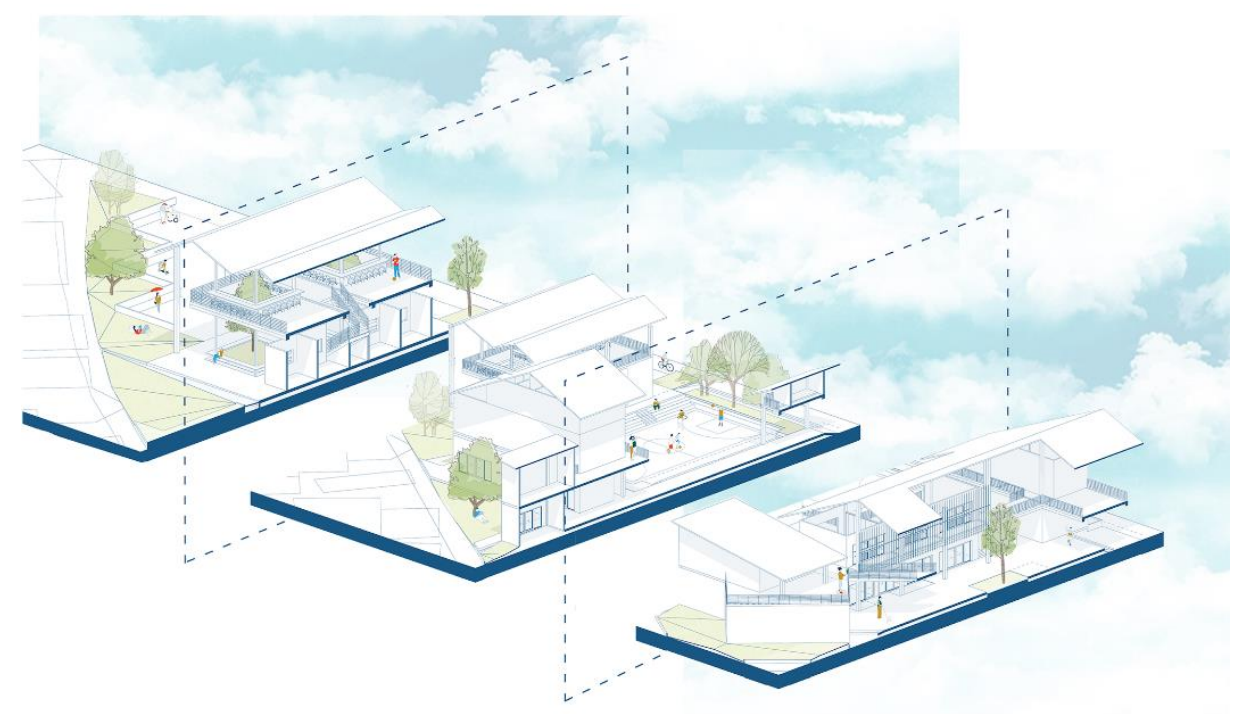

Gambar 15. Pembagian Zona Bangunan

Sumber: Dok. penulis, 2020

\section{Social Space}

Dasar dari bangunan merupakan terbentuknya ruang aktivitas yang juga sekaligus menjadi ruang sosial warga. Dari ruang jajanan PKL, tangga menghadap lapangan utama, hingga 'gang' sebagai center dari program-program di zona 1 


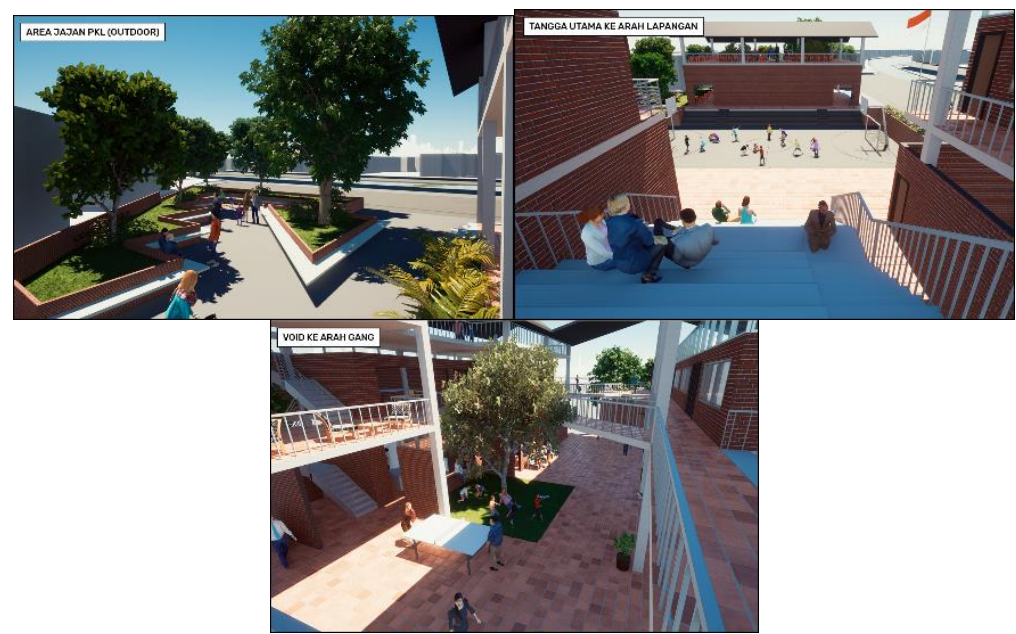

Gambar 16. Suasana Ruang Sosial yang Terbentuk sumber: dok. penulis, 2020

Dalam tampak bangunan terlihat atap-atap pelana yang menggambarkan panorama perkampungan kota dengan berbagai ketinggian atap. Kisi-kisi kayu yang ditumbuhi tanaman rambat, serta dinding mural karya para anak-anak warga.

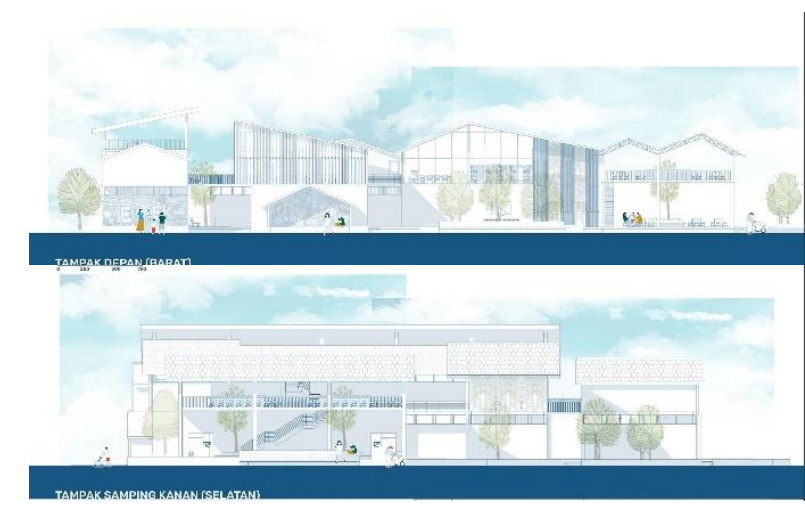

Gambar 17. Tampak Depan dan Samping Kanan Bangunan Sumber: Dok. penulis, 2020

\section{KESIMPULAN DAN SARAN}

\section{Kesimpulan}

Dengan pendekatan analisa kelokalan dan kegotong royongan dari warga lokal kampung kota, sebuah ruang bersama (commons) dapat menjadi menjadi 'rumah kedua' bagi warga lokal dan juga menjadi ruang ketiga bagi para penggunanya. Proyek Ruang Ketiga 'Balai Budaya Kolektif dan Anak Paseban' memberikan ruang bersama publik terancang, bagi warga Kampung Kramat Sawah dan Kramat Lontar di Kelurahan Paseban, Kecamatan Senen. Berdasarkan partisipasi komunitas dalam aspek sosial-budaya-rekreasional yang juga dapat memberikan edukasi nonformal dan penghidupan ekonomi produktif bagi warganya melalui pemberdayaan komunitas. Sehingga dapat diraihnya kampung yang selain sebagai ruang produksi sosial habitat, tetapi juga produktif secara ekonomi, sesuai dengan karakter kelokalannya.

\section{Saran}

Penulis menyarankan untuk adanya penelitian lebih lanjut mengenai kehidupan di kampung kota lainnya dan untuk berharap untuk jika ada pembangunan bagi warganya, baik dari pemerintah maupun non-pemerintah, dapat didasarkan dari pengumpulan data dari tempat 
tersebut, karena setiap tempat, khususnya di Kampung Kota Jakarta memiliki karakternya masing-masing.

\section{REFERENSI}

Amalina, F.H. (2017). Kampung Tongkol dan Masa Depan Penataan Permukiman Kumuh di Perkotaan Indonesia. Nekropolis. Diakses 16 Oktober 2020, dari $<$ https://medium.com/nekropolis/kampung-tongkol-dan-masa-depan-penataanpermukiman-kumuh-di-perkotaan-indonesia-6844bed0f2ec>

Coates, N. (2012). Architectural Digest: Narrative Architecture. Oxford: Wiley.

Dalton, J.H., et al. (2007). Community Psychology: Linking Individuals and Communities. Belmont: Thomson Publisher.

Friedmann, J. (2007). The Wealth of Cities: Towards an asset-based development of newly urbanizing regions. UN-HABITAT Lecture Award Series, No. 1. Nairobi: United Nations Human Settlements Programme. Diakses dari $<$ https://unhabitat.org/sites/default/files/download-managerfiles/The\%20Wealth\%20of\%20cities\%20Towards\%20an\%20assets based\%20development\%20of\%20 newly\%20urbanizing\%20regions.pdf>

Gumilang, I. (2018). Kompendium Kehidupan Kampung Kota Jakarta. Jakarta: Rujak Center for Urban Studies.

Kapoor, J. (2018). The Welcome Resurgence of 'Third Places'. Launch Capital. Diakses 28 Agustus 2020, dari<https://medium.com/jaykapoornyc/the-welcome-resurgence-of-thirdplaces-5149b97eec82>

Oldenburg, R. (1999). The Great Good Place: Cafes, Coffee Shops, Bookstores, Bars, Hair Salons, and Other Hangouts at the Heart of a Community. Cambridge: Marlowe \& Company.

Pameran Ini Kampung, Museum M.H. Thamrin. (12-12-2018 s/d 05-01-2019). Jakarta: Rujak Center for Urban Studies

Project for Public Spaces. (2007). What is Placemaking?. Diakses dari $<$ https://pps.org/article/what- is-placemaking >

Psarra, S. (2009). Architecture and Narrative: The Formation of Space and Cultural Meaning. London: Routledge.

Rujak Centre for Urban Studies. (2018). Kenal Kampung Kota. Jakarta: Rujak Centre for Urban Studies

Salim, H. (2018). tHEORY 101: Aldo Rossi's Collective Memory. Arch.ive. Diakses dari <https:// medium.com/@heryantosalim/theory-101-aldo-rossis-collective-memory-1caa3e00606>

Tisskink, F.E. (2016). Narrative-driven Design: Roles of narratives for designing the built environment. Delft: TU Delft. Diakses dari <https://repository.tudelft.nl/islandora/object/uuid: $\quad$ 60309156-4e32-4b11-a01bcaba2b8a2913/datastream/OBJ12/download> 
